\title{
Modular Catalysts for the Enantioselective Allylation of Aldehydes
}

Metal-Mediated Synthesis

Key Words

asymmetric synthesis

allylation

modular ligands
$\mathrm{RCHO}+$<smiles>C=CCBr</smiles>

$5-10 \% \mathrm{CrCl}_{2}, 10-15 \% \mathrm{Et}_{3} \mathrm{~N}, 10 \mathrm{~mol} \% 1$ TMSCI (2 equiv), $M n(0)$ (2 equiv), THF, r.t., $20 \mathrm{~h}$<smiles>[R]C(O)CC=C</smiles>

up to $95 \%$ ee<smiles>CC(C)[C@H](NC(=O)[C@@H]1CCCN1C(=O)OC(C)(C)C)C1=N[C@@H](Cc2ccccc2)CO1</smiles>

Significance: The formerly developed $\mathrm{Mn}-\mathrm{Cr}(\mathrm{II})$ mediated allylation of aldehydes for the first time has been performed in an enantioselective variant using a set of modular amino acid-derived ligands. Enantioselectivities of up to $95 \%$ were achieved after screening of different catalyst diastereomers.
Comment: A modular approach for the search for new enantioselective ligands is very promising as it offers a rational method for improving the enantioselectivity by changing the building blocks at will. Modular ligands can be developed for most metal-catalyzed reactions, starting usually from available naturally occurring materials, in several simple steps. 